Original Research Paper

\title{
Assessing the Trend of Climate Change in the Western Nepal
}

\author{
${ }^{1}$ Purna Bahadur Khand, ${ }^{2}$ Vikash Kumar KC, ${ }^{3}$ Ananta Raj Dhungana and ${ }^{4}$ Surya Mani Dhungana \\ ${ }^{I}$ School of Business, Pokhara University, Pokhara, Nepal \\ ${ }^{2}$ Department of Statistics PN Campus, Tribhuvan University, Pokhara, Nepal \\ ${ }^{3}$ School of Development and Social Engineering, Pokhara University, Pokhara, Nepal \\ ${ }^{4}$ Department of Agricultural Economics and Agribusiness Management, \\ Agriculture and Forestry University, Bharatpur, Nepal
}

Article history

Received: 01-11-2020

Revised: 21-12-2020

Accepted: 22-12-2020

Corresponding Author:

Purna Bahadur Khand

School of Business, Pokhara

University, Pokhara, Nepal

Email: purnabahadurkhand@gmail.com

\section{Introduction}

The Fourth Assessment Report (AR4) has clearly mentioned that humans are the primary cause to buildup of Greenhouse Gases (GHG) in the atmosphere. The concentration of GHG which contains Carbon Dioxide $\left(\mathrm{CO}_{2}\right)$, methane $\left(\mathrm{CH}_{4}\right)$, Nitrous Oxide $\left(\mathrm{N}_{2} \mathrm{O}\right)$, water vapor $\left(\mathrm{H}_{2} \mathrm{O}\right)$ and some other gases has increased the atmospheric temperature of the Earth. Their effects, together with those of other anthropogenic drivers, have been detected throughout the climate system and are more likely to have been the dominant cause of the observed warming since the mid-20th century (IPCC, 2007). Globally averaged combined land and ocean surface temperature data shows a warming of 0.85 [0.65 to 1.06$]^{\circ} \mathrm{C}$ over the period 1880 to 2012. Rate of warming per decade over the recent past few years $(1998-2012)$ was $0.05[-0.05 \text { to } 0.15]^{\circ} \mathrm{C}$. Warming of the climate system is unequivocal and many of the observed changes are unprecedented over the last couples of decades. Changes in many extreme weather and climate events have been observed such as a decrease in cold temperature extremes, an increase in warm temperature extremes, an increase in extreme high sea levels and an increase in the number of heavy precipitation events in a number of regions (IPCC, 2014).

Climate is a primary determinant of agricultural productivity, especially in the case of developing countries like Nepal where agriculture is basically dependent on natural circumstances against the controlled environmental condition unlike in developed countries. 
Therefore, climate change would influence crop yield to a greater extent in developing countries. Plausible scenarios in climate change such as increasing temperature, changes in precipitation, climate extremes like drought, flood and landslides and higher $\mathrm{CO}_{2}$ concentrations will directly affect crop yields (Abrol and Ingram, 1996; Adams et al., 1998; 2001; Mendelsohn, 2008; Mendelsohn and Reinsborough, 2007; Mendelsohn et al., 1994). In Nepal, during 1971-2014, the annual maximum and annual minimum temperature trends are $0.056[0.05$ to $0.58]^{\circ} \mathrm{C} /$ year and $0.002[-0.009 \text { to } 0.014]^{\circ} \mathrm{C} /$ year respectively, along with annual precipitation trends -1.333 [-0.072 to -0.324$] \mathrm{mm} /$ year (DHM, 2017). Similar study shows, during 1976-2005, annual maximum temperature and minimum temperature trends are 0.05 and $0.03^{\circ} \mathrm{C} /$ year respectively (PAN, 2009).

Nepal is no exception in being country vulnerable to the impacts of climate change due to its fragile mountain ecosystem, weak geological condition and diverse nature climate. Nepal may experience a great impact even with the slight changes over the natural climate system. Moreover, being a developing country, Nepal has low adaptive capacity to cope with the effects of climate change. Different sectors such as agriculture, health, water resources, biodiversity and forest, etc. which are affected due to climate change are directly linked to livelihoods of Nepalese people. This clearly indicates that country like Nepal needs to prepare for adoption to the climate change. The policy and action should focus to adopt a combined strategy of reducing GHG emission and adaptation to the impacts of climate change consistently at national and local level (Maharjan and Joshi, 2012; NAST, 2013; Regmi and Adhikari, 2007; Shrestha et al., 2017).

Further, among all sectors in Nepal, the agriculture sector which is the most vulnerable sector to climate change, has impacted agricultural productivity mainly through three primary channels: Increasing temperatures; climate variability and associated changes in the timing, intensity and volume of rainfall; and raising the levels of carbon dioxide. There is much uncertainty about the magnitude of these changes and the consequent effects on agriculture because of extreme complexities of downscaling and projecting climate variables at high elevations and in monsoonal geographies. Nevertheless, there is evidence that observed changes in temperatures and soil moisture that are already occurring and are adversely impacting agriculture in many parts of Nepal. It has impacted almost all the development sectors of Nepal and people's livelihoods base. The climatic risks and uncertainties are exerting additional pressures to communities across Nepal. Stories about drying water sources, women traveling longer distance to collect water and firewood, declining crop productivity, or communities relying under the impact of floods and other climate-induced disasters, highlight the urgent need to manage this adverse impact (MoE, 2011; Pant, 2011; Shrestha, 2000).
Nepal needs very appropriate policy responses for adaptation to the climate change challenges. More important for the sustainable adaptation to the climate change impact is to empower people and organize local efforts using local resources. Observing the climate change and its impact by the local people and arranging adaptation by themselves for the vulnerabilities is the best way to cope. Though, there are vast number of studies on climate change and its impact on agricultural sector at national and international level, there still lacks such studies at local level and, until and unless if the lower cohorts of income and education people who are highly impacted and vulnerable do not perceive and self-adopt for the adverse impact, any program at any level is not sustainable and merely useless. Hence, this study focuses how climate change occurs at local level in the western development region of Nepal. Thus, the aim of this paper is to characterize the temporal variability and trend of maximum temperature, minimum temperature and rainfall over the period of last few decades in order to accurately represent local climate diversities. An understanding of the climate diversities and trend at local level would help to anticipate impacts of the climate change and making adaption strategy to the people at that specific area. It also helps both the governments at national level and provincial level to make specific climate change impact adaption policy at the local level than from the information of national level average climate characteristics. Section 2 of this paper describes the methodology of the study where data sources and methods are discussed. This is followed by results in the section 3 . The paper ends with a summary of the results, discussion and conclusions.

\section{Materials and Methods}

Monthly data on maximum temperature, minimum temperature and rainfall for five stations from the western development region, namely, Chame, Lumle, Khudibazar, Khairenitar and Dumkauli of Manang, Kaski, Lumjung, Tanahu and Nawalparasi districts respectively, obtained from Department of Hydrology and Meteorology (DHM) of Nepal are considered. DHM established in 1962 is under the Ministry of Energy, Water Resources and Irrigation of Nepal. It is also a focal point for the Intergovernmental Panel on Climate Change (IPCC). The main objective of DHM is to collect hydrological and meteorological data throughout the country and process, publish and disseminate the data to users. As a member of the World Meteorological Organisation (WMO), DHM contributes to the global exchange of meteorological data on a regular basis. DHM is equipped with several data collection facilities based on different technologies, such as, wireless communication, meteor burst, radiosonde, Satellite Distribution Information System (SADIS), Weather Fax 
and satellite picture receiving system. Wireless system connects the capital city Kathmandu to the stations spread over Nepal for climatic and hydrological data whereas the Global Telecommunication System (GTS) links DHM to the global meteorological community. Although the department has controlled the validity and reliability of the data, frequent interruption of obtaining regular data causes number of missing data. Similarly, DHM is facing chalanges to set up its metrological stations in the high hill regions. Data availability for these three variables is not uniform and ranges the earlier since 1970 to the latest 2018. To measure the change in the climatic variables, first data were deseasonalized using classical multiplicative technique taking moving average of twelve periods and central moving average (Dagum, 2010; Harvey, 1985; Hyndman and Athanasopoulos, 2018; Kendall and Ord, 1990). For trend analysis of climatic variables, this study uses both parametric and non-parametric methods where Ordinary Least Squared (OLS) regression is taken as parametric and Mann-Kendall test and Sen's slope are taken as nonparametric methods.

\section{OLS Regression}

A simple linear trend can be computed using the linear regression of climatic variable $X$, which are monthly maximum temperature, minimum temperature and rainfall in this study, on time $t$, with intercept $\beta_{0}$, slope $\beta_{1}$ and error term $\varepsilon$ (Greene, 2003; Hirsch et al., 1982; Longobardi and Villani, 2010; Mudelsee, 2010), as follows:

$$
X=\beta_{0}+\beta_{1} t+\varepsilon
$$

The coefficient $\beta_{1}$, which is the slope of the regression line, is a trend for the climatic variables. A null hypothesis $H_{0}, \beta_{1}=0$, is tested using the t-statistic. The null hypothesis is rejected if the $t$-statistic i.e., $\hat{\beta}_{1} / \operatorname{se}\left(\hat{\beta}_{1}\right)$ is greater than critical two-tail of $\mathrm{t}$ distribution with $\alpha$ significance level and 1 degrees of freedom as there is only one independent variable in the regression. Here, $\hat{\beta}_{1}$ is the estimated value of $\beta_{1}$. Though the parametric method is considered a powerful method for testing a trend; however, the normality, non-autocorrelation and homoskedasticity of residuals are some of the basic requirements in this method (Helsel and Hirsch, 1992).

\section{Mann-Kendall Test}

This technique, commonly known as the Kendall's tau statistic, has been widely used to test for randomness against trend in climatic and hydrologic time series (Kendall, 1975; Mann, 1945; Van Belle and Hughes, 1984; Yu et al., 1993; Yue and Wang, 2004). According to the test, the null hypothesis $H_{0}$ states that the deseasonalized data $\left(X_{1}, X_{2}, \ldots, X_{n}\right)$ are a sample of $n$ independent and identically distributed random variables. The alternative hypothesis $H_{1}$ of a two-sided test is that the distribution is not independent and identically distributed. For performing the test, the statistic $S$ is given as:

$S=\sum_{i=2}^{n} \sum_{j=i}^{n-1} \operatorname{sign}\left(X_{i}-X_{j}\right)$

In the equation, $S$ is sum of signs of the differences between any two sequential observations in the series, $X_{i}$ and $X_{j}$ are the sequential data values $(j=i+1)$. A positive value of $S$ indicates an upward trend and a negative value of $S$ indicates downward trend. Sign for $\left(X_{i}-X_{j}\right)$ is given as:

$\operatorname{sign}\left(X_{i}-X_{j}\right)=\left\{\begin{array}{r}+1 i f\left(X_{i}-X_{j}\right)>0 \\ 0 i f\left(X_{i}-X_{j}\right)=0 \\ -1 i f\left(X_{i}-X_{j}\right)<0\end{array}\right.$

Similarly, the standardize statistical test $\left(Z_{M K}\right)$ can be computed as:

$Z_{M K}=\left\{\begin{array}{l}(S-1) / \sqrt{\operatorname{var}(S)} \text { if } S>0 \\ 0 \quad \text { if } S=0 \\ (S+1) / \sqrt{\operatorname{var}(S)} \text { if } S<0\end{array}\right.$

Its variance of $S$ is given as:

$\operatorname{var}(S)=\frac{n(n-1)-\Sigma_{T} T(T-1)(2 T+5)}{18}$

The notation $T$ is the extent of any given tie and $\Sigma_{T}$ denotes the summation over all ties. In the standard variate, for two-sided test for trend, null hypothesis $H_{0}$ is accepted if $\left|Z_{M K}\right|<Z_{\alpha / 2}$, where, $Z_{\alpha / 2}$ standard normal cumulative distribution at $\alpha$ level of significance. Similarly, a positive value of $Z_{M K}$ indicates an upward trend and a negative value of $Z_{M K}$ indicates downward trend. The non-parametric test like Mann-Kendall test are widely used to assess the significance of trends in climatic time series such as temperature and precipitation. The scope of non-parametric tests compared to parametric tests is that these are suitable for non-normally distributed and censored data that found more often in climatic time series. However, the serial independence of the time series is still needed for nonparametric statistical test (Yue et al., 2002).

\section{Sen's Slope}

If a linear trend is present in a time series, then the true slope (change per unit time) can be estimated by using a simple non-parametric procedure developed by (Sen, 1968a-b). The slope $S$ is computed by: 
$S=$ median $\left(\frac{X_{i}-X_{j}}{i-j}\right)$

where, $i=1,2, \ldots, n-1 ; j=2,3, \ldots, n$; and $i<j$.

Finally, $S$ is tested by a two-sided test at the $\alpha$ level of significance. Again, a positive value of $S$ indicates an upward trend and a negative value of $S$ indicates downward trend. This method is very popular in meteorology and climatology for measuring temperature and precipitation trends over time (Kahya and Kalayci, 2004; Machiwal et al., 2019; Martinez et al., 2012; Tian et al., 2017; Van Belle and Hughes, 1984). It is distribution free and even permits for merely ordinal measurement scales. This method could also be used with missing data and remain unaffected by outliers or gross errors (Van Belle and Hughes, 1984).

\section{Results}

Nepal is divided into five physiographic regions, terai, siwalik, middle hill, high hill and, mountain or himalaya. The elevation ranges from $60 \mathrm{~m}$ Mean Sea Level (MSL) in the terai to over $8000 \mathrm{~m} \mathrm{MSL}$ in the himalaya including the world's highest peak-the Mt. Everest of $8848 \mathrm{~m} \mathrm{MSL}$ in the north. Terai is a low-lying plain in the south and northwards, middle and high hills are elongated east-west with a series of valleys breaks, such as Kathmandu, Pokhara, Dang and Surkhet and, mountains rise slowly to the north and make up the snow-capped high himalaya. Significant variations exist among these five physiographic regions in terms of climate. Temperature varies with topographic variations and increases from south in the terai to north in mountains and the average temperature decreases by $6^{\circ} \mathrm{C}$ for every $1000 \mathrm{~m}$ gain in altitude. Similarly, there are marked spatial and temporal variations of rainfalls in both north-south and east-west. Monsoon rain is most abundant in the east and declines westwards, while winter rains are higher in the northwest and declines south-westwards. Eighty percent of the precipitation falls in Nepal comes in the form of summer monsoon rain from June to September (Jha, 1992; MoEnv, 2010; Team, 2009; PAN, 2009).

Table 1 shows the physiographic regions of the sampled stations along with elevation, latitude and longitude respectively. This study focused only western development region of the country and, from the region, only 5 districts have been selected, which could not represent all the physiographic regions. Further, there are limited number of meteorological stations in the mountains compared to other physiographic regions.

Table 1: Elevation, latitude, longitude and physiographic regions of the stations

\begin{tabular}{llllll}
\hline Station no & Station name & Elevation $(\mathrm{m})$ & Latitude $\left({ }^{\circ} \mathrm{N}\right)$ & Longitude $\left({ }^{\circ} \mathrm{E}\right)$ & Physiographic regions \\
\hline 0816 & Chame & 2680 & 28.6 & 84.2 & $\mathrm{HH}$ \\
0814 & Lumle & 1738 & 28.3 & 83.8 & MH \\
0802 & Khudibazar & 838 & 28.3 & 84.4 & SW \\
0815 & Khairenitar & 515 & 28.0 & 84.1 & SW \\
0706 & Dumkauli & 183 & 27.7 & 84.2 & TR
\end{tabular}

TR, SW, MH and HH stand for terai, siwalik, middle hill and high hill respectively

Table 2: Summary statistics-maximum temperature, minimum temperature and rainfall

\begin{tabular}{|c|c|c|c|c|c|c|c|}
\hline \multirow[b]{2}{*}{ Station } & \multirow[b]{2}{*}{ Obs } & \multirow[b]{2}{*}{ Mean } & \multirow[b]{2}{*}{ SD } & \multirow[b]{2}{*}{ Min } & \multirow[b]{2}{*}{ Max } & \multicolumn{2}{|l|}{$95 \% \mathrm{CI}$} \\
\hline & & & & & & Lower & Upper \\
\hline \multicolumn{8}{|l|}{ Maximum } \\
\hline Chame & 423 & 16.8544 & 4.1850 & 5.5 & 24.5 & 16.4544 & 17.2543 \\
\hline Lumle & 588 & 20.0639 & 3.8974 & 11.2 & 27.4 & 19.7482 & 20.3975 \\
\hline Khudibazar & 588 & 26.8515 & 4.0656 & 17.5 & 38.4 & 26.5222 & 27.1807 \\
\hline Khairenitar & 588 & 29.0144 & 4.6227 & 11.5 & 36.7 & 28.6400 & 29.3888 \\
\hline Dumkauli & 514 & 30.8116 & 4.5547 & 19.0 & 39.8 & 30.4169 & 31.2062 \\
\hline \multicolumn{8}{|l|}{ Minimum } \\
\hline Chame & 423 & 4.7279 & 4.7585 & -5.3 & 13.1 & 4.2731 & 5.1827 \\
\hline Lumle & 588 & 12.0082 & 4.4978 & 2.5 & 18.5 & 11.6439 & 12.3725 \\
\hline Khudibazar & 588 & 14.8233 & 5.3597 & -1.9 & 22.5 & 14.3880 & 15.2585 \\
\hline Khairenitar & 588 & 16.8554 & 5.8039 & 1.2 & 25.2 & 16.3854 & 17.3255 \\
\hline Dumkauli & 514 & 18.7117 & 6.1357 & 6.5 & 26.5 & 18.1800 & 19.2434 \\
\hline \multicolumn{8}{|l|}{ Rainfall } \\
\hline Chame & 458 & 79.2749 & 78.6836 & 0.0 & 439.2 & 72.0497 & 86.5001 \\
\hline Lumle & 588 & 448.2791 & 548.2825 & 0.0 & 2149.6 & 403.8712 & 492.6870 \\
\hline Khudibazar & 588 & 275.9726 & 322.4298 & 0.0 & 1427.5 & 249.8576 & 302.0877 \\
\hline Khairenitar & 565 & 188.5563 & 212.1112 & 0.0 & 1130.8 & 171.0288 & 206.0838 \\
\hline Dumkauli & 576 & 195.8009 & 244.9197 & 0.0 & 1225.8 & 175.7573 & 215.8447 \\
\hline
\end{tabular}


Table 2 shows the descriptive statistics of the monthly observed maximum temperature, minimum temperature and rainfall for five different stations Chame, Lumle, Khudibazar, Khairenitar and Dumkauli of Manang, Kaski, Lumjung, Tanahu and Nawalparasi districts respectively from the western development region of Nepal. It reveals the mean value, standard deviation, minimum and maximum values of the climatic variables along with the $95 \%$ confidence interval. Data availability for these three variables are not uniform and ranges earlier since January, 1970 to the latest December, 2018. There were a few missing data for some stations which were filled by temporal interpolations.

Mean of maximum monthly temperature has decreased with the increase of altitude and it is the highest $\left(30.8116^{\circ} \mathrm{C}\right)$ for Dumkauli and the lowest $\left(16.8544^{\circ} \mathrm{C}\right)$ for Chame. Variation in the temperature which is measured by standard deviation is the highest $\left(4.6227^{\circ} \mathrm{C}\right)$ for Khairenitar during the study period. Dumkauli has the highest observed maximum monthly temperature $\left(39.8^{\circ} \mathrm{C}\right)$ and Chame has the lowest observed maximum monthly temperature $\left(5.5^{\circ} \mathrm{C}\right)$. Similarly, mean of minimum monthly temperature is the lowest $\left(4.7279^{\circ} \mathrm{C}\right)$ for Chame and the highest $\left(18.7117^{\circ} \mathrm{C}\right)$ for Dumkauli and, the temperature variation is the highest $\left(6.1357^{\circ} \mathrm{C}\right)$ for Dumkauli. Chame has the lowest observed minimum monthly temperature $\left(-5.3^{\circ} \mathrm{C}\right)$ and Dumkauli has the highest observed minimum monthly temperature $\left(6.5^{\circ} \mathrm{C}\right)$. For observed average monthly rainfall, Lumle station became both the highest mean $(448.2791 \mathrm{~mm})$ and the highest variation (548.2825 $\mathrm{mm}$ ) rainfall station and, Chame station became also both the lowest mean $(79.2749 \mathrm{~mm})$ and the lowest variation $(78.6836 \mathrm{~mm})$ rainfall station.

The monthly trends of maximum temperature, minimum temperature and rainfall are shown in Fig. 1. Both, monthly maximum temperature and monthly minimum temperature pattern have shown that temperatures are decreasing with the increasing altitudes that is temperatures are decreasing from Dumkauli which is in terai region to Chame in high himalaya. Monthly average rainfall is lowest for the Chame and the highest for the Lumle among the five stations. Lumle station is the highest rainfall recorded station in the country. The rainfall pattern of Nepal is dominated by the monsoonal circulation along with the topography. More than three quarters of annul precipitation occurs due to this system.
The outcomes of monthly trends of maximum temperature in degree centigrade per month (in ${ }^{\circ} \mathrm{C} /$ month) with corresponding p-values to show if the trends are statistically significant obtained from the three different statistical tests of which one, the parametric test, obtained from OLS regression and the other two, non-parametric tests, obtained from Mann-Kendall and Sen's slope for the five stations of the western development region of Nepal, namely, Chame, Lumle, Khudibazar, Khairenitar and Dumkauli are given in Table 3. Monthly data for the three stations, Lumle, Khudibazar and Khairenitar, are obtained from January, 1970 to December, 2018, of total 588 months duration. Remaining two stations, Chame and Dumkauli, are of different duration. Monthly data for Chame is obtained from July, 1977 to September, 2012, of total 423 months duration, whereas for Dumkauli, it is taken from March, 1976 to December, 2018, of total 514 months duration. These monthly maximum temperatures are the mean of daily maximum temperatures.

All five stations have statistically significant increasing trends for monthly maximum temperature obtained from OLS regression. Among these, Chame has the highest $\left(0.0078^{\circ} \mathrm{C} / \mathrm{month}\right.$ or $0.9360^{\circ} \mathrm{C} /$ decade $)$ and Dumkauli has the lowest $\left(0.0021^{\circ} \mathrm{C} / \mathrm{month}\right.$ or $0.2520^{\circ} \mathrm{C} /$ decade) increasing temperature trends. Nonparametric tests, namely, Mann-Kendall and Sen's slope, have also shown that the all mentioned stations have statistically significant positive trends for the monthly maximum temperatures. Sen's slope shows consistent results for the same stations of the highest and the lowest trends as in the OLS regression, however, it shows slower trend than the OLS trend which are $0.0062^{\circ} \mathrm{C} /$ month or $0.7440^{\circ} \mathrm{C} /$ decade for Chame and $0.0013^{\circ} \mathrm{C} / \mathrm{month}$ or $0.1560^{\circ} \mathrm{C} /$ decade for Dumkauli.

Table 4 gives magnitudes of monthly minimum temperature trends $\left({ }^{\circ} \mathrm{C} /\right.$ month $)$ obtained from the three different statistical tests for the five stations. Monthly minimum temperature data for Chame is obtained from July, 1977 to September, 2012, of total 423 months duration; for Lumle and Khairenitar from January, 1970 to December, 2018, of total 588 month duration; for Khudibazar from January, 1970 to September, 2018, of total 585 month duration; and for Dumkauli from March, 1976 to December, 2018, of total 514 month duration.

Table 3: Monthly maximum temperature trend

\begin{tabular}{|c|c|c|c|c|c|c|c|}
\hline \multirow[b]{2}{*}{ Station } & \multirow{2}{*}{$\begin{array}{l}\text { Monthly } \\
\text { max_temp }\end{array}$} & \multicolumn{2}{|l|}{ OLS } & \multicolumn{2}{|c|}{ Mann-Kendall } & \multicolumn{2}{|c|}{ Sen's slope } \\
\hline & & Trend & P-value & Tau & P-value & Slope & $\mathrm{P}$-value \\
\hline Chame & $1977-2012$ & 0.0078 & 0.000 & 0.3010 & 0.000 & 0.0062 & 0.000 \\
\hline Lumle & $1970-2018$ & 0.0042 & 0.000 & 0.3690 & 0.000 & 0.0038 & 0.000 \\
\hline Khudi Bazar & $1970-2018$ & 0.0056 & 0.000 & 0.4500 & 0.000 & 0.0052 & 0.000 \\
\hline Khairenitar & $1970-2018$ & 0.0029 & 0.000 & 0.1880 & 0.000 & 0.0024 & 0.000 \\
\hline Dumkauli & $1976-2018$ & 0.0021 & 0.000 & 0.0972 & 0.000 & 0.0013 & 0.004 \\
\hline
\end{tabular}



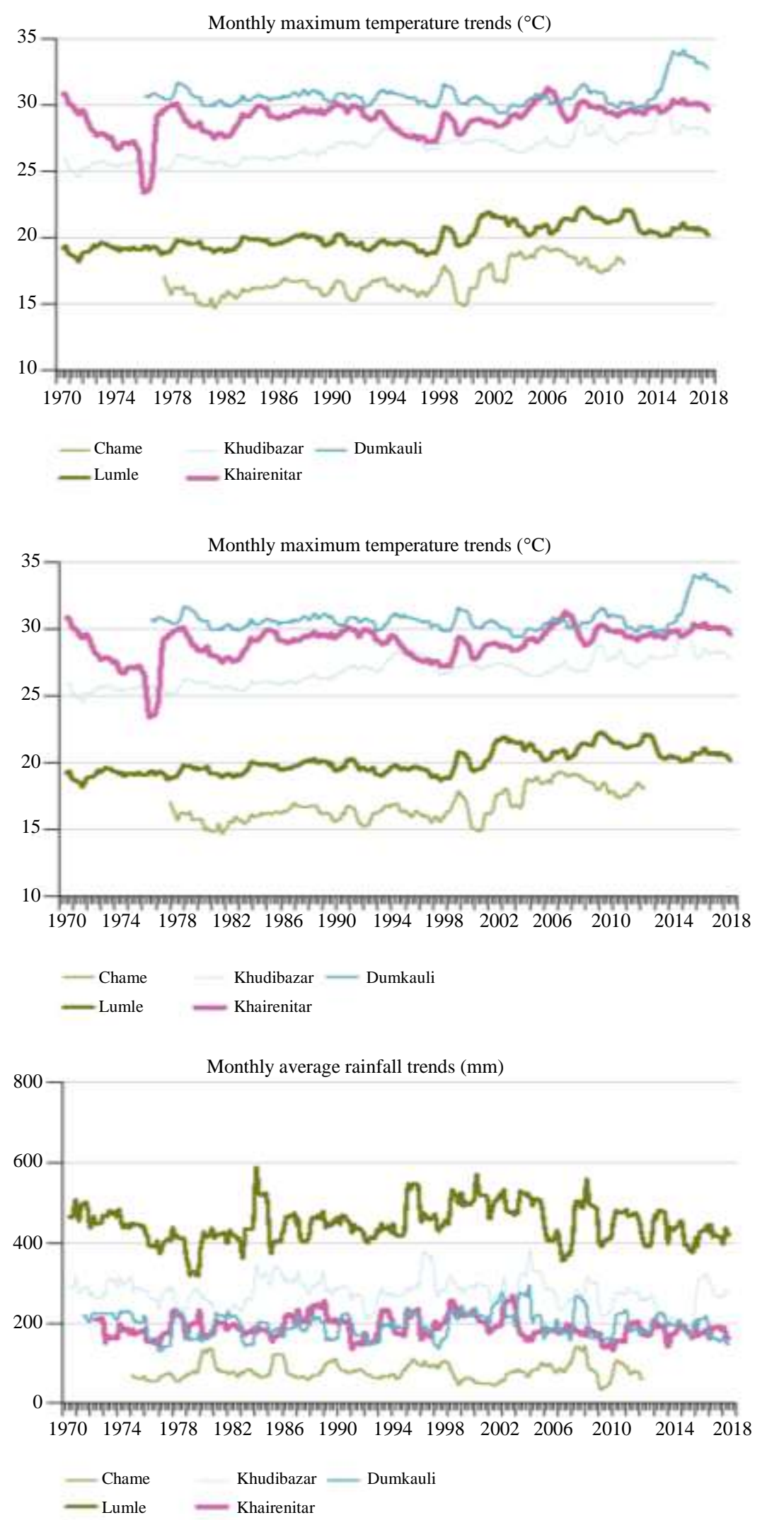

Fig. 1: Monthly trends of maximum temperature, minimum temperature and rainfall 
Table 4: Monthly minimum temperature trend

\begin{tabular}{|c|c|c|c|c|c|c|c|}
\hline \multirow[b]{2}{*}{ Station } & \multirow{2}{*}{$\begin{array}{l}\text { Monthly } \\
\text { max_temp }\end{array}$} & \multicolumn{2}{|l|}{ OLS } & \multicolumn{2}{|c|}{ Mann-Kendall } & \multicolumn{2}{|c|}{ Sen's slope } \\
\hline & & Trend & P-value & Tau & P-value & Slope & P-value \\
\hline Chame & $1977-2012$ & 0.0001 & 0.939 & -0.0218 & 0.504 & -0.0005 & 0.504 \\
\hline Lumle & $1970-2018$ & 0.0001 & 0.680 & 0.0506 & 0.066 & 0.0003 & 0.066 \\
\hline Khudi Bazar & $1970-2018$ & 0.0045 & 0.000 & 0.2850 & 0.000 & 0.0035 & 0.000 \\
\hline Khairenitar & $1970-2018$ & 0.0024 & 0.000 & 0.1660 & 0.000 & 0.0014 & 0.000 \\
\hline Dumkauli & $1976-2018$ & 0.0024 & 0.000 & 0.1630 & 0.000 & 0.0014 & 0.000 \\
\hline
\end{tabular}

Table 5: Monthly average rainfall trend

\begin{tabular}{|c|c|c|c|c|c|c|c|}
\hline \multirow[b]{2}{*}{ Station } & \multirow{2}{*}{$\begin{array}{l}\text { Monthly } \\
\text { rainfall }\end{array}$} & \multicolumn{2}{|l|}{ OLS } & \multicolumn{2}{|c|}{ Mann-Kendall } & \multicolumn{2}{|c|}{ Sen's slope } \\
\hline & & Trend & $\mathrm{P}$-value & Tau & $\mathrm{P}$-value & Slope & P-value \\
\hline Chame & $1974-2012$ & -0.0162 & 0.589 & -0.0425 & 0.175 & -0.0211 & 0.175 \\
\hline Lumle & $1970-2018$ & -0.0665 & 0.443 & -0.0175 & 0.526 & -0.0291 & 0.526 \\
\hline Khudibazar & $1970-2018$ & -0.1085 & 0.088 & -0.0562 & 0.042 & -0.0644 & 0.042 \\
\hline Khairenitar & 1971-2018 & -0.0747 & 0.101 & -0.0710 & 0.012 & -0.0712 & 0.012 \\
\hline Dumkauli & 1971-2018 & 0.0166 & 0.766 & -0.0232 & 0.409 & 0.0000 & 0.409 \\
\hline
\end{tabular}

Similar to the monthly maximum temperatures, monthly minimum temperatures are also the mean of daily minimum temperatures. OLS regression shows that only three stations, namely, Khudibazar, Khairenitar and Dumkauli have statistically significant increasing trends for monthly minimum temperature. Among these, Khudibazar has the highest $\left(0.0045^{\circ} \mathrm{C} /\right.$ month or $0.5400^{\circ} \mathrm{C} /$ decade) and both Khairenitar and Dumkauli have the same $\left(0.0024^{\circ} \mathrm{C} /\right.$ month or $0.2880^{\circ} \mathrm{C} /$ decade $)$ increasing temperature trends. Both non-parametric tests, Mann-Kendall and Sen's slope, have shown consistent results with OLS results that the same three stations, Khudibazar, Khairenitar and Dumkauli, have statistically significant positive trends for the monthly minimum temperatures. Sen's slope has also shown the same stations of the highest and the lowest trends but at slower rate than in the OLS trend. Sen's slope shows that Khudibazar has a trend of $0.0035^{\circ} \mathrm{C} / \mathrm{month}$ or $0.4200^{\circ} \mathrm{C} /$ decade and, Khairenitar and Dumkauli have trend of $0.0014^{\circ} \mathrm{C} / \mathrm{month}$ or $0.1680^{\circ} \mathrm{C} /$ decade.

Table 5 gives magnitudes of monthly average rainfall trends in millimeter per month ( $\mathrm{mm} / \mathrm{month}$ ) with corresponding $\mathrm{p}$-values obtained from the three different statistical tests, OLS regression, Mann-Kendall and Sen's slope for the five stations from the western development region of Nepal. Monthly average rainfall data for Chame is obtained from August, 1974 to September, 2012, of total 458 months duration; for Lumle and Khudibazar from January, 1970 to December, 2018, of total 588 month duration; for Khairenitar from December, 1971 to December, 2018, of total 565 month duration; and for Dumkauli from January, 1971 to December, 2018, of total 576 month duration. Similar to the monthly maximum temperatures and monthly minimum temperature, monthly average rainfalls are also the mean of daily rainfalls.
OLS regression shows that all five stations have no statistically significant trends for monthly average rainfall. However, Mann-Kendall and Sen's slope, have shown Khudibazar and Khairenitar stations have statistically significant trends for the monthly average rainfall. Sen's slope has shown that Khudibazar and Khairenitar stations have decreasing trends of -0.0644 $\mathrm{mm} / \mathrm{month}$ or $-7.7280 \mathrm{~mm} /$ decade and -0.0712 $\mathrm{mm} / \mathrm{month}$ or $-8.5440 \mathrm{~mm} /$ decade respectively for the monthly average rainfall.

\section{Discussion}

In the study, monthly maximum temperature has increased for all stations, whereas, monthly minimum temperature has increased only in three stations, namely Khudibazar, Khairenitar and Dumkauli. This increasing trend of monthly maximum temperature for all five stations and no significant monthly minimum temperature trend for Chame and Lumle stations follow the national level trends of annual and seasonal maximum temperature and no specific trend of minimum temperature (DHM, 2017; 2015; PAN, 2009; Shrestha et al., 1999). As the data for monthly minimum temperature for the remaining two stations, namely Chame and Lumle, show statistically significant positive trend, these stations do not follow the national level trends. Both the spatial distribution for maximum and minimum monthly temperatures follow the topography that is the highest temperatures are observed at Dumkauli station in the tarai region and the lowest temperatures observed at Chame station in the high hill region. Similarly, increasing trend for monthly maximum temperature and monthly minimum temperature follow more or less to the topography. It has increased for monthly maximum temperature and decreased for monthly minimum temperature with the increasing altitude of the stations. 
Also, increasing trend for the maximum temperature is faster than the decreasing trend for minimum temperature (DHM, 2017; 2015; PAN, 2009).

Lumle station became both the highest mean and the highest variability for observed average monthly rainfall and, Chame station became also both the lowest mean and the lowest variability rainfall station. Significant trends are observed for average monthly rainfall only at two stations, Khudibazar and Khairenitar and these two have decreasing trends. OLS regression shows all five stations have statistically insignificant trends which is consistent with the national level annual rainfall trend (DHM, 2017; Nayava, 2004; PAN, 2009). The precipitation pattern of Nepal is dominated by the two weather systems, summer monsoon circulation and westerly circulation and its interaction with the topography. The summer monsoon precipitation is most abundant in the southeast and declines westwards, whereas, the westerly-derived winter precipitation is higher in the northwest and declines south-westwards. Eighty percent of its annual precipitation falls in the country in the form of summer monsoon during June to September. The southern side of the Annapurna mountain regions are observed as the highest annual precipitation sites with more than $5400 \mathrm{~mm}$ per year, whereas leeside of the same mountain regions are observed as the lowest annual precipitation sites with less than $200 \mathrm{~mm}$ per year (Kansakar et al., 2004; Nayava, 2004; Shrestha, 2000).

\section{Conclusion}

Climate change over Nepal is both in temporal and spatial dimensions. The country is a highly vulnerable and more likely adverse impacts of climate change, thus, adaptation to climate change must be at high priority in the coming days. As the country has huge diverse climatic variations and the climate change is impacting at the grassroots level differently, without understanding the changing climate pattern at each local level, adaptation planning will not be effective. For effective adaptation planning, localized information on climate change and their specific impacts are imperative to understand. Considering the importance of climate pattern of local level, this paper aims to assess the temporal trend of maximum temperature, minimum temperature and rainfall of the five stations which represent local climate diversities of western development region of Nepal. It also compares the result with the national level trend. The assessment is based on the observed meteorological data published by Department of Hydrology and Meteorology of Nepal for the period 1970-2018, though the availability of data range are not uniform for different climatic variables, applying OLS regression and other two non-parametric methods, Mann-Kendall and Sen's slope. As most of the metrological and hydrological data have a strong seasonal component (Kendall and Ord, 1990), first, these data are deseasonalized to assess the general long-term characteristics of the time series. The stydy finds that maximum temperature has increased in all stations; the minimum temperature has increased in Khudibazar, Khairenitar and Dumkauli stations; and rainfall has increased in Chame and, decreased in Lumle and Khairenitar stations. Further, both maximum temperature and minimum temperature have increased faster in higher altitudes; and rainfall has decreased slower in lower altitudes. Both Mann-Kendall and Sen's slope tests are consistent with the result.

Most of the studies in Nepal about the climate change impact are national level. There are very few updated and local level studies about the trends of temperatures and precipitation at regional level and local level. This study may fulfill this gap and could be a useful source of information for making climate change adaption strategy at local level.

\section{Acknowledgement}

This study is funded by University Grants Commission (UGC) of Nepal under the collaborative research grants on climate change and its impact on agriculture sector: Evidence from western Nepal (CRG-73/74-Ag and F-01). We highly acknowledge the UGC, Nepal.

\section{Author's Contributions}

Purna Bahadur Khand: Contributed to introduction, data analysis, results, discussion and conclusion.

Vikash Kumar KC: Contributed to methodology, discussion and conclusion.

Ananta Raj Dhungana and Surya Mani Dhungana: Coordinated with the university grant commission, collected secondary data from the Department of Hydrology and Meteorology of Nepal and contributed in writing up final manuscript.

\section{Ethics}

The authors declare no conflicts of interest and confirm that the manuscript has been submitted solely to this journal and is not published, in press, or submitted elsewhere.

\section{References}

Abrol, Y. P., \& Ingram, K. T. (1996). Effects of higher day and night temperatures on growth and yields of some crop plants. Global climate change and agricultural production. Direct and indirect effects of changing hydrological, pedological and plant physiological processes. Wiley, Chichester, 124-140. 
Adams, R. M., Hurd, B. H., Lenhart, S., \& Leary, N. (1998). Effects of global climate change on agriculture: an interpretative review. Climate research, 11(1), 19-30.

Adams, R. M., Hurd, O. B. H., \& Stratus Consulting, C. O. (2001). Global climate change and its impact on agriculture.

Dagum, E. B. (2010). Time series modeling and decomposition. Statistica, 70(4), 433-457.

DHM, N. (2015). Study of climate and climatic variation over Nepal. Ministry of science, technology and environment, Government of Nepal.

DHM. (2017). Observed climate trend analysis in the districts and physiographic regions of Nepal (1971-2014).

Greene, W. H. (2003). Econometric analysis. Pearson Education India.

Harvey, A. C. (1985). Trends and cycles in macroeconomic time series. Journal of Business \& Economic Statistics, 3(3), 216-227.

Helsel, D. R., \& Hirsch, R. M. (1992). Statistical methods in water resources (Vol. 49). Elsevier.

Hirsch, R. M., Slack, J. R., \& Smith, R. A. (1982). Techniques of trend analysis for monthly water quality data. Water resources research, 18(1), 107-121.

Hyndman, R. J., \& Athanasopoulos, G. (2018). Forecasting: principles and practice. OTexts.

IPCC. (2007). Climate Change 2007: Synthesis Report. Contribution of Working Groups I, II and III to the Fourth Assessment Report of the Intergovernmental Panel on Climate Change. Geneva: IPCC.

IPCC. (2014). Climate Change 2014: Synthesis Report. Contribution of Working Groups I, II and III to the Fifth Assessment Report of the Intergovernmental Panel on Climate Change. Geneva: IPCC.

Jha, P. K. (1992). Environment and man in Nepal. sn].

Kahya, E., \& Kalayci, S. (2004). Trend analysis of streamflow in Turkey. Journal of Hydrology, 289(1-4), 128-144.

Kansakar, S. R., Hannah, D. M., Gerrard, J., \& Rees, G. (2004). Spatial pattern in the precipitation regime of Nepal. International Journal of Climatology: A Journal of the Royal Meteorological Society, 24(13), 1645-1659.

Kendall, M. G. (1975). Rank Correlation Methods. London: Charles Griffin \& Co.

Kendall, M., \& Ord, J. K. (1990). Time series, 3rd edn London. UK: Edward Arnold.

Longobardi, A., \& Villani, P. (2010). Trend analysis of annual and seasonal rainfall time series in the Mediterranean area. International journal of Climatology, 30(10), 1538-1546.
Machiwal, D., Gupta, A., Jha, M. K., \& Kamble, T. (2019). Analysis of trend in temperature and rainfall time series of an Indian arid region: comparative evaluation of salient techniques. Theoretical and Applied Climatology, 136(1-2), 301-320.

Maharjan, K. L., \& Joshi, N. P. (2012). Climate change, agriculture and rural livelihoods in developing countries with reference to Nepal. Hiroshima International Center for Environment Cooperation (HICEC), IDEC, Hiroshima University.

Mann, H. B. (1945). Nonparametric tests against trend. Econometrica: Journal of the econometric society, 245-259.

Martinez, C. J., Maleski, J. J., \& Miller, M. F. (2012). Trends in precipitation and temperature in Florida, USA. Journal of Hydrology, 452, 259-281.

Mendelsohn, R. (2008). The impact of climate change on agriculture in developing countries. Journal of Natural Resources Policy Research, 1(1), 5-19.

Mendelsohn, R., \& Reinsborough, M. (2007). A Ricardian analysis of US and Canadian farmland. Climatic change, 81(1), 9-17.

Mendelsohn, R., Nordhaus, W. D., \& Shaw, D. (1994). The impact of global warming on agriculture: a Ricardian analysis. The American economic review, 753-771

MoE. (2011). Climate change policy, 2011. Kathmandu: Ministry of Environment (MoE), Government of Nepal.

MoEnv. (2010). National Adaptation Programme of Action to Climate Change. Kathmandu: Ministry of Environment.

Mudelsee, M. (2010). Climate time series analysis: classical statistical and bootstrap methods. Heidelberg: Springer.

NAST. (2013). Environment and Natural Resources. Kathmandu: Nepal Academy of Science and Technology.

Nayava, J. L. (2004). Temporal variations of rainfall in Nepal since 1971 to 2000 . Journal of Hydrology and Meteorology, 1, 24-33.

Team, N. C. V. S. (2009). Vulnerability Through the Eyes of the Vulnerable: Climate Change Induced Uncertainties and Nepal's Development Predicaments. Institute for Social and Environmental Transition-Nepal (ISET-N).

PAN. (2009). Temporal and spatial variability of climate change over Nepal (1976-2005). Kathmandu: Practical Action Nepal.

Pant, K. P. (2011). Economics of climate change for smallholder farmers in Nepal: a review. Journal of Agriculture and Environment, 12, 113-126. 
Regmi, B. R., \& Adhikari, A. (2007). Human Development Report 2007. Climate change and human development-risk and vulnerability in a warming world. Country case study-Nepal, New York, United Nations Development Programme.

Sen, P. K. (1968a). Estimates of the regression coefficient based on Kendall's tau. Journal of the American statistical association, 63(324), 1379-1389.

Sen, P. K. (1968b). On a class of aligned rank order tests in two-way layouts. The Annals of Mathematical Statistics, 39(4), 1115-1124.

Shrestha, A. B., Bajracharya, S. R., Sharma, A. R., Duo, C., \& Kulkarni, A. (2017). Observed trends and changes in daily temperature and precipitation extremes over the Koshi river basin 1975-2010. International Journal of Climatology, 37(2), 1066-1083.

Shrestha, A. B., Wake, C. P., Mayewski, P. A., \& Dibb, J. E. (1999). Maximum temperature trends in the Himalaya and its vicinity: an analysis based on temperature records from Nepal for the period 1971-94. Journal of climate, 12(9), 2775-2786.
Shrestha, M. L. (2000). Interannual variation of summer monsoon rainfall over Nepal and its relation to Southern Oscillation Index. Meteorology and Atmospheric Physics, 75(1-2), 21-28.

Tian, J., Liu, J., Wang, J., Li, C., Nie, H., \& Yu, F. (2017). Trend analysis of temperature and precipitation extremes in major grain producing area of China. International Journal of Climatology, 37(2), 672-687.

Van Belle, G., \& Hughes, J. P. (1984). Nonparametric tests for trend in water quality. Water resources research, 20(1), 127-136.

Yu, Y. S., Zou, S., \& Whittemore, D. (1993). Nonparametric trend analysis of water quality data of rivers in Kansas. Journal of Hydrology, 150(1), 61-80.

Yue, S., \& Wang, C. (2004). The Mann-Kendall test modified by effective sample size to detect trend in serially correlated hydrological series. Water resources management, 18(3), 201-218.

Yue, S., Pilon, P., \& Cavadias, G. (2002). Power of the Mann-Kendall and Spearman's rho tests for detecting monotonic trends in hydrological series. Journal of hydrology, 259(1-4), 254-271. 